\title{
THE EFFECTS OF WULST LESIONS ON SIMPLE VISUAL DISCRIMINA- TION PERFORMANCE IN THE PIGEON
}

\author{
DFNIS M. PARKER* and JUAN D. DFI,IUS** \\ Department of Psychology, University of Durham (Great Britain) \\ Present adresses: \\ *Department of Psychology, King's College, University of Aberdeen AB9 2UB (Great \\ Britain) \\ **Psychologisches Institut, Ruhr-Universitat, 4630 Bochum (Federal Republic of Germany)
}

\begin{abstract}
Parker, D.M. and Delius, J.D., 1980. The effects of Wulst lesions on simple visual discrimination performance in the pigeon. Behav. Processes, 5: 151-159.

Pigeons with lesions involving the hyperstriatum accessorium, hyperstriatum intercalatus superior and hyperstriatum dorsale were compared with sham operated controls on acquisition of a simple colour/brightness discrimination. Correct and incorrect choices together with choice latencies were recorded. The lesioned birds' performance on the discrimination aspects of the task was not inferior to controls. However, the choice times of the lesioned group were significantly longer than controls. The within session pattern of choice latencies was also significantly different, with the lesioned birds beginning each session with longer latencies than controls but ending the session with choice latencies equivalent to controls. The lesion effect is attributed to damage to a mechanism concerned with arousal or response facilitation within the anterior Wulst.
\end{abstract}

\section{INTRODUCTION}

The Wulst is a clearly visible protruberance on the dorsal surface of the avian brain and it is usually taken to include the multi-laminate hyperstriatal areas of the telencephalon. This region is known to receive visual (Rougeul, 1957; Karten, 1969; Parker and Delius, 1972), and cutaneous (Delius and Benetto, 1972) sensory projections. The majority of behavioural studies of hyperstriatal function have concentrated on birds' ability to solve visual discrimination problems when they have sustained damage within this region. While initial results (Zeigler, 1963) indicated that hyperstriatal damage may impair brightness and pattern vision, subsequent investigators have found little impairment in simple colour, brightness and pattern discriminations (Pritz et al., 1970; Hodos et al., 1973). Indeed the deficiences that may be found are more apparent when using a successive discrimination paradigm where they can be attributed to interference with response inhibition processes rather than discrimination 
capacity (Macphail, 1969). It might be concluded then, that on easily acquired tasks involving visual discrimination, birds with Wulst lesions behave as efficiently as controls and it is only when an extra difficulty, such as reversal, is introduced (Stettner and Schultz, 1967) that consistent losses became evident. However, it is apparent that under some circumstances one measure of a Wulst lesioned bird's performance may reveal no impairment while another measure will (Macphail, 1971). With this in mind it was decided to re-examine the performance of Wulst lesioned pigeons on a simple simultaneous visual discrimination task but also to collect data on the birds' discrimination rate to examine in some detail the temporal aspects of the birds' performance.

\section{METHODS}

\section{Subjects}

Eight adult pigeons obtained from a commercial supplier were allowed to feed ad libitum for 14 days following their arrival in the laboratory.

\section{Apparatus and procedure}

The experimental chamber consisted of a Standard Grason Stadler Pigeon Box. 'The response keys were $2.5 \mathrm{~cm}$ in diameter and located $15 \mathrm{~cm}$ apart and $22 \mathrm{~cm}$ above the cage floor. The access to the grain hopper was located $6 \mathrm{~cm}$ above the cage floor midway between the response keys. Stimuli were projected onto the keys using miniature projectors mounted on the back of each key. The positive stimulus was red (Wratten 25) and the negative stimulus was blue (Wratten $47 \mathrm{~b}$ ). The stimuli were first matched for brightness $\left(15 \mathrm{~cd} / \mathrm{m}^{2}\right)$ and then the brightness of the blue was reduced by $0.5 \mathrm{log}$ units by inserting the appropriate neutral density filter. The pigeon's spectral sensitivity is known to be relatively less in the blue end of the spectrum than in the red as compared with human's (Blough, 1957). Thus the stimuli differed in hue and brightness. Correct and incorrect responses and response latencies were recorded on a print-out counter/timer.

The pigeons, housed individually, were reduced to $80 \%$ of their free feeding weight and shaped to peck at both response keys. When the birds had made 10 rewarded pecks to both response keys shaping was completed and the birds were allowed to regain their free feeding body weight. Four animals from the eight were randomly selected for the experimental group, the remainder serving as controls. The four control birds were anaesthetized with Equithesin (intramuscular, $0.25 \mathrm{ml} / 100 \mathrm{~g}$ ), the scalp opened and the bone overlying the hyperstriatum removed but no brain tissue was removed in these animals. Following the same operative procedure, in the experimental animals the dura was lifted and cut and hyperstriatal tissue aspirated using a vacuum pump and a fine glass capillary. The aim was to remove as much as possible of the visual projection area in the hyperstriatum described by Revzin (1969). The bone was then plugged with absorbable gelatine soaked in thrombin, the skin sutured and the birds returned to their home cages. After 1 week of feeding ad libitum 
the birds were gradually reduced to $80 \%$ of their free feeding weight and discrimination training commenced 3 weeks after surgery.

\section{Discrimination training}

The training paradigm was a simultaneous discrete trial method. Both positive and negative stimuli were presented simultaneously on different keys and were switched randomly from side to side between trials using a Gellerman sequence (Gellerman, 1933). If the animal chose correctly (the red stimulus) the keys were blanked and the grain hopper presented for $5 \mathrm{~s}$. Following an incorrect choice the keys were blanked and nothing further occurred until the start of the next trial which commenced $15 \mathrm{~s}$ after the last key peck made by the bird. The time which elapsed between the presentation of the stimuli and the birds' response was automatically recorded. Thirty trials/day were given.

\section{Histology}

Following the termination of the experiment the pigeons were sacrificed and their heads perfused through the carotids and fixed in formalin. The brains were hardened in $10 \%$ formalin, impregnated and blocked in paraffin wax and sectioned $(20 \mu)$, every 10 th section being mounted and stained with cresyl violet. The lesions were reconstructed on coronal standard drawings of the pigeon brain based on the atlas of Karten and Hodos (1967).

\section{RESULTS}

Coronal sections through the anterior part of the intact pigeon brain are illustrated in Fig. 1 (Key) together with the lesion reconstructions of the experimental animals. It can be seen that the most anterior part of the Wulst (a term which properly refers to the clear protruberance on the dorsal aspect of the forebrain lying between the vallecula and the midline, but is often taken, as here, to refer to the various hyperstriatal structures) was extensively damaged in all experimental animals. The proportionate area of damage shrinks as the level of the sections moves posteriorly. The structures of main interest to the present study were the hyperstriatum accessorium and the hyperstriatum intercalatus superior which contain the main visual projection from the nucleus opticus principalis thalami (Revzin, 1969; Perisic et al., 1971; Karten et al., 1973). These structures were substantially damaged in birds 78 and 81 , to an intermediate level in bird 82 and mildly in bird 83 except in the most anterior regions. The damage in all birds was confined to the dorsal hyperstriatal structures except for slight invasion of the hyperstriatum ventrale in the most anterior region of bird 78 .

The discrimination performance of experimental and control groups is shown in Fig. 2 in terms of mean per cent correct for successive blocks of 10 trials. It can be seen that acquisition of the discrimination is extremely rapid. By the last block of the first day's training the experimental group are already performing at $88 \%$ correct and by the last block of the second day's training 

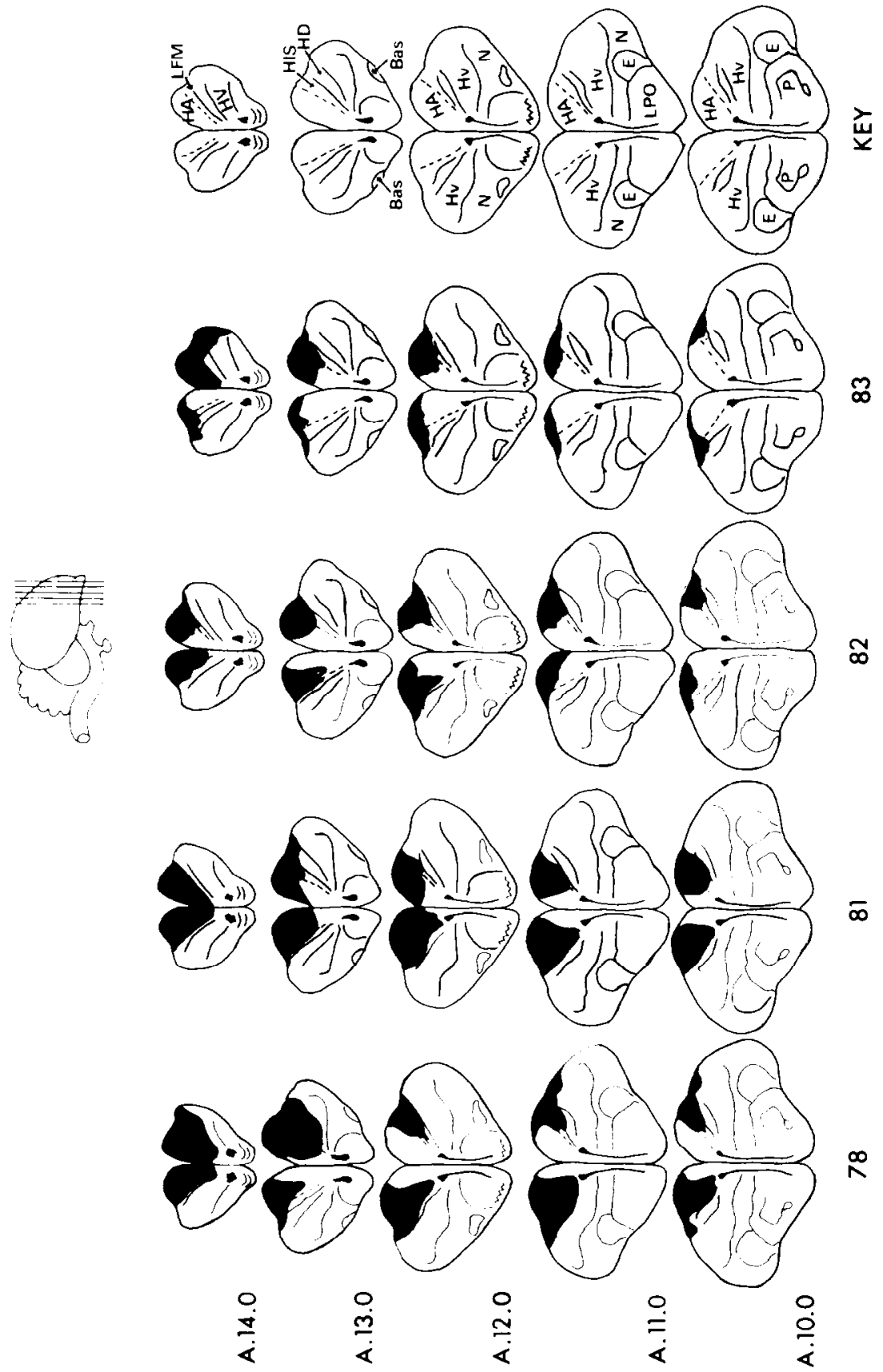
both experimentals and controls are performing at well over $90 \%$ correct. Birds 78 and 81 which had the most extensive damage performed at $90 \%$ correct by the third block of the first day's session, while bird 83 which sustained the least damage only achieved this level of performance in the last block of the second day's training. The choice performance of both experimental and control groups is so similar on this type of simple discrimination task that percent correct or errors are obviously insensitive to the effects of these lesions and so statistical analysis of these measures was not pursued.

The mean choice latencies for experimental and control groups for each day's training are shown in Fig. 3. The mean latencies of the two groups differ substantially on the first 2 days of training but on the third and fourth
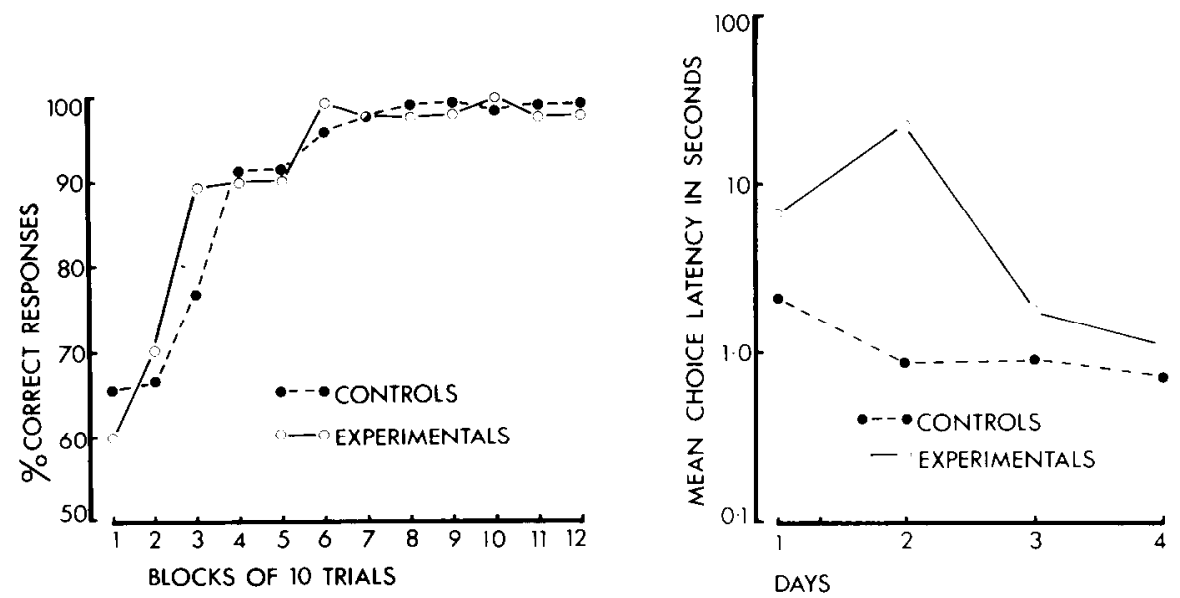

Fig. 2. Mean percent correct performance on the discrimination task for control and experimental groups (ordinate) plotted against successive blocks of 10 trials (abscissa).

Fig. 3. Mean choice latencies for control and experimental groups for each day's experimental session ( 30 trials/session). Note the logarithmic scale on the ordinate.

Fig. 1. Coronal sections through the intact pigeon brain (extreme right) together with reconstructions of the lesion extents, shown in black, in the four experimental birds, 78 , 81,82 and 83 . Letters and numbers on the left refer to the corresponding plane of the section in the Atlas of Karten and Hodos (1967), and the approximate position of the sections are also indicated in the drawing at the top of the figure. Abbreviations in the key sections: Bas, nucleus basalis; E, ectostriatum; HA, hyperstriatum accessorium; HD, hyperstriatum dorsale; HIS, hy perstriatum intercalatus superior; $\mathrm{Hv}$, hy perstriatum ventrale; LFM, lamina frontalis suprema; LPO, lobus parolfactorius; $N$, neostriatum; $P$, paleostriatum primitivum. 


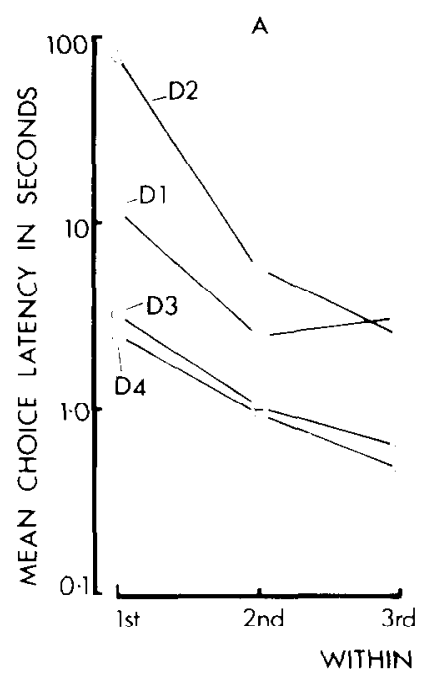

B

$\bullet--\bullet$ CONTROLS

- EXPERIMENTALS
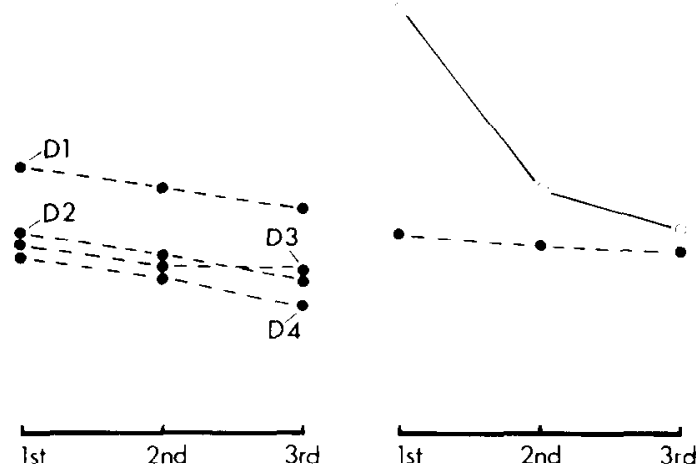

lst

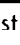

c

Fig. 4. Mean choice latencies for experimental (A) and control groups (B) for each block of 10 trials (1st, 2 nd, 3rd) within each day's experimental session. D1, D2. etc. refer to Day 1, Day 2, etc. In $C$ the grand (collapsed across the 4 day's training) means for each of these within session blocks of trials are shown in order to facilitate understanding of the significant within session interaction ef fect obtained.

days the choice times of the experimentals approach those of the controls. The mean choice latencies for each bird for each block of 10 trials were subjected to an analysis of variance after the data had been logarithmically transformed (because the distribution showed a clear positive skew). The analysis revealed a significant overall effect of the lesion $(F=8.29 ;$ d.f. $=1,6 ; P<0.05)$ and a significant change in latency over successive days of training ( $F=10.24$; d.f. $=$ $3,18 ; P<0.01)$. The analysis also revealed a significant within session change in latency $(F=23.23$; d.f. $=2.12 ; P<0.01)$ as well as a significant interaction between lesion effect and the within session change $(F=10.92$; d.f. $=2.12$; $P<0.01$ ). The meaning of these latter two differences can be appreciated by examination of Fig. 4, in which the mean choice latencies for each block of 10 trials over each of the sessions are plotted. It can be seen that in both experimental and control groups latencies show a tendency to fall during the course of a day's training and the analysis of variance confirms the significance of this effect (Fig. 4A, B). The magnitude of this change is greater in the experimental group who begin each session with much longer choice times than the controls but approach the controls' latencies in the final block of each session, hence the significant lesion by within session interaction.

In summary then, choice measures on a simple discrimination task did not reveal differences between control and experimental subjects. Analysis of choice latencies, however, revealed significant and systematic differences between the behaviour of lesioned and non-lesioned groups. Of incidental interest is the finding from transfer tests administered to the birds at the end of the 
discrimination learning described here, which revealed that they all responded in terms of hue and not brightness (Parker, 1971).

\section{DISCUSSION}

The rapid learning in the present experiment of both experimental and control groups probably reflects the distinctiveness of colour as a cue for pigeons (Jones, 1954). Indeed, the initial process of acquisition may be marginally faster in lesioned than control groups where the stimuli are easily differentiated (see blocks 1-3 of Fig. 1), an observation that is also apparent in the data of Macphail (1969). While the percent correct scores of the experimental birds gives no indication that they are impaired by the lesions, examination of the choice time data shows that they can be readily distinguished from controls. Overall, choice latencies are significantly longer in lesioned than in control birds. This is not the first occasion on which attention has been drawn to a discrepancy between two different performance measures in pigeons with Wulst lesions. Macpail (1971) noted that while birds were still responding to the negative stimulus in a go-no-go discrimination, measures of behavioural contrast indicated that they were learning the essential features of the discrimination task as readily as controls. In the present experiment it may be argued that the longer choice latencies in the lesioned birds reflect a general processing deficit so that the analysis of the essential features of the task took them longer. Apart from the fact that such a processing deficit would be expected to reveal itself in the initial choice scores, whereas in fact lesioned birds are if anything marginally more efficient than controls, this explanation does not take account of the pattern of latency differences. If the lesioned birds' capacity to analyze the features of the experimental situation was reduced, then they would be expected to show a reasonably constant temporal deficit across the experimental session. This does not occur. The experimental group begin the session with much longer response latencies than controls, but as the session proceeds the gap closes and in fact on two occasions they end the session with choice times either equal to or marginally faster than controls. Whatever factor(s) accounts for the differences between experimentals and controls it is evidently one which can change during the period of an experimental session (10-15 min), and so a constant processing deficit does not seem a likely candidate. Examination of the choice latencies of the control group indicates that they show a gradual but significant decline in latency within sessions. The within sessions change in the experimental group appears to be a greatly exaggerated version of a similar tendency. This response facilitation effect is slow to start in the experimental group but when responding is underway there is rapid acceleration. Macphail (1969) noted that lesions within the anterior hyperstriatum appeared to produce an excess of behavioural inhibition. The birds frequently failed to respond and trials were discontinued. Part of the problem in Macphail's (1969) experiments probably arose from the fact that the birds were placed in the apparatus at the start of each trial and 
they were less isolated from the experimenter than the birds in the present study. The present results, then, support Macphail's (1969) contention that the anterior hyperstriatum of birds contains a mechanism concerned with response facilitation. He also speculated that the posterior hyperstriatal regions contained mechanisms concerned with response inhibition. Our results offer no evidence concerning this hypothesis, but it is interesting to note that Salzen et al. (1975) found that the duration of post-startle freezing behaviour was significantly shorter in chicks with lesions of the posterior Wulst than in controls.

The data reported in this paper offer support for a theory of hyperstriatal function proposed in detail by Salzen and Parker (1975) which suggested that the hyperstriatum was concerned with arousing and maintaining orientation within a stimulus field. The lesioned birds in the present study are clearly defective in initiating behaviour that leads to rewards and only acquire the efficient performance of the controls after considerable exposure to the situation.

\section{A CKNOWLEDGEMENTS}

The work was supported by the Science Research Council, London. While writing, J.D.D. was supported by the Deutsche Forschungsgemeinschaft, Bonn, through its Sonderforschungsbereich 114.

\section{REFERENCES}

Blough, D.S., 1957. Spectral sensitivity in the pigeon. J. Opt. Soc. Am., 47: 827-833.

Delius, J.D. and Bennetto, K., 1972. Cutaneous sensory projections to the avian forebrain. Brain Res, 37: 205-221.

Gellerman, L.W., 1933. Chance orders of alternating stimuli in visual discrimination learning. J. Genet. Psychol., 42: 206-208.

Hodos, W., Karten, H.J. and Bonbright, J.C., Jr., 1973. Visual intensity and pattern discrimination after lesions of the thalamofugal pathway in pigeons. J. Comp. Neurol., 148: $447-468$.

Jones, L.V., 1954. Distinctiveness of colour, form and position cues for pigeons. J. Comp. Physiol. Psychol., 47: 253-257.

Karten, H.J., 1969. The organisation of the avian telencephalon and some speculations on the phylogeny of the amniote telencephalon. Ann. N.Y. Acad. Sci., 167: 164-179.

Karten, H.J. and Hodos, W., 1967. A Stereotaxic Atlas of the Brain of the Pigeon (Columba 1.). John Hopkins Press, Baltimore, MD, 193 pp.

Karten, H.J., Hodos, W., Nauta, W.J.H. and Revzin, A.M., 1973. Neural Connections of the "visual Wulst" of the avian telencephalon: experimental studies in the pigeon (Columba livia) and owl (Speotypto cunicularia). J. Comp. Neurol., 150: 253-278.

Macphail, E.M., 1969. Avian hyperstriatal complex and response facilitation. Commun. Behav. Biol., 4: 129-137.

Macphail, E.M., 1971. Hyperstriatal lesions in pigeons: effects on response inhibition, behavioural contrast, and reversal learning. J. Comp. Physiol. Psychol., 75: 500-507.

Parker, D.M., 1971. Electrophysiological and behavioural studies of vision in the Pigeon. Ph.D. Thesis, University of Durham, 177 pp. 
Parker, D.M. and Delius, J.D., 1972. Visual evoked potentials in the forebrain of the pigeon. Exp. Brain Res., 14: 198-209.

Perisic, M., Mihailovic, J. and Cuenod, M., 1971. Electrophysiology of contralateral and ipsilateral visual projections to the Wulst in pigeon. Int. J. Neurosci., 2: 1-8.

Pritz, M.B., Mead, W.R. and Northcutt, R.G., 1970. The effects of Wulst ablations on colour, brightness and pattern discrimination in pigeons (Columba livia). J. Comp. Neurol., 140: 81-100.

Revzin, A.M., 1969. A specific visual projection area in the hyperstriatum of the pigeon (Columba livia). Brain Res., 15: 246-249.

Rougeul, A., 1957. Exploration Osillographique de la Voie Visuell du Pigeon. Foulon, Paris.

Salzen, E.A. and Parker, D.M., 1975. Arousal and orientation functions of the avian telencephalon. In: P. Wright, P.G. Caryl and D.M. Vowels (Editors), Neural and Endocrine Aspects of Behaviour in Birds. Elsevier. Amsterdam, pp. 205-242.

Salzen, E.A., Parker, D.M. and Williamson, A.M., 1975. A forebrain lesion preventing imprinting in domestic chicks. Exp. Brain Res., 24: 145-157.

Stettner, L.J. and Schultz, W.J., 1967. Brain lesions in birds: effects on discrimination acquisition and reversal. Science, 155: 1689-1692.

Zeigler, H.P., 1963. Effects of endbrain lesions upon visual discrimination learning in pigeons. J. Comp. Neurol., 120: 161-182. 